Archived version from NCDOCKS Institutional Repository http://libres.uncg.edu/ir/asu/

\title{
Appalachl̈ăn
}

B O O N E, N O R T H C A R O L I N A

\section{Land Cover Classification Using Landsat TM Imagery In The Tropical Highlands: The Influence Of Anisotropic Reflectance}

\author{
By: J.D. Colby and P.L. Keating
}

\begin{abstract}
Despite the tremendous attention given to conservation projects in the Neotropics, few published studies have documented remote sensing studies in tropical highland areas. Even fewer publications have addressed the use of topographic normalization methods in these regions. This article discusses the influence of anisotropic reflectance patterns on land cover classification for two study areas characterized by very rugged terrain and high relief. Landsat Thematic Mapper subscenes for sites in both Costa Rica and Ecuador were corrected using both Lambertian and non-Lambertian models. While use of the Lambertian model proved inappropriate for these mountainous areas, application of the non-Lambertian model enhanced classification accuracies.
\end{abstract}

Colby, J.D. and Keating, P.L. (1998). Land Cover Classification Using Landsat TM Imagery in the Tropical Highlands: The Influence of Anisotropic Reflectance. International Journal of Remote Sensing, 19(8):1479-1500. (May 20, 1998) Published by Taylor \& Francis (ISSN: 1366-590). DOI: 10.1080/014311698215306. Publisher version of record available at: https://www.tandfonline.com/doi/abs/10.1080/014311698215306 


\title{
Land cover classification using Landsat TM imagery in the tropical highlands: the influence of anisotropic reflectance
}

\begin{abstract}
Despite the tremendous attention given to conservation projects in the Neotropics, few published studies have documented remote sensing studies in tropical highland areas. Even fewer publications have addressed the use of topographic normalization methods in these regions. This article discusses the infl uence of anisotropic refl ectance patterns on land cover classifi cation for two study areas characterized by very rugged terrain and high relief. Landsat Thematic Mapper subscenes for sites in both Costa Rica and Ecuador were corrected using both Lambertian and non-Lambertian models. While use of the Lambertian model proved inappropriate for these mountainous areas, application of the non-Lambertian model enhanced classifi cation accuracies.
\end{abstract}

\section{Introduction}

During the last 20 years, remotely sensed data have been used extensively to monitor environmental change and to map land cover (Booth 1989, Lillesand and Kiefer 1994). Remote sensing techniques have frequently been applied to the study of tropical ecosystems, due in part to the growing recognition of conservation issues and the potential impacts of global climate change. Regional-scale changes in forest cover, for example, have often been monitored with NOAA AVHRR imagery (e.g. Townshend and Justice 1986, Malingreau et al. 1989), which has a $1.1 \mathrm{~km}$ or coarser spatial resolution. These researchers have identified numerous deforested areas in both Africa and the Amazon Basin.

Additionally, many tropical remote sensing studies have utilized Landsat MultiSpectral Scanner (MSS) data (Sader et al. 1990). While numerous image processing techniques have been developed to map cover types in lowland rain forests using MSS data, most of these projects have been only partially successful. MSS imagery appears to have little utility for assessing forest clearing accurately, nor does it enable one to distinguish among various successional stages (Tucker et al. 1984, Sader et al. 1990).

The superior spatial and spectral resolutions of Landsat Thematic Mapper (TM) imagery may enable researchers to produce high quality maps of vegetation types and zones of human disturbance (Sader et al. 1990). TM data have been utilized in the tropics primarily during the last 7 years (e.g. Vanclay and Preston 1990, Mulders et al. 1992, Mausel et al. 1993, Hill and Foody 1994, Moran et al. 1994, Paradella 
et al. 1994, Skole et al. 1994, Brondizio et al. 1996). These studies demonstrate the utility of TM imagery for mapping complex tropical land cover in areas located below $2000 \mathrm{~m}$ elevation.

Few researchers have used remote sensing techniques to study tropical highlands. Studies involving the application of TM imagery in humid tropical mountain environments have noted the strong influence of topography on spectral classification (e.g. Sader et al. 1989, Echavarria 1993, Garcia and Alvarez 1994, Hill and Foody 1994). In many Latin American countries, these regions cover more than $10 \%$ of the country (e.g. Balslev 1988) and include a very heterogenous mixture of vegetation. Detailed land cover maps for these areas are scarce, and rates of anthropogenic disturbances have rarely been quantified. Given the high rate of deforestation in most tropical montane areas (Young and León 1995, Keating 1997), it seems appropriate to develop techniques for mapping both the major vegetation types and areas of anthropogenic disturbance. Accurate land cover maps would enable environmental scientists to monitor land degradation and would also provide a basis for modelling long-term environmental changes.

Discriminating among different types of land cover in areas of high relief using remotely sensed data has been difficult (Justice et al. 1980, Colby 1991). Except in flat terrain, the natural surface variable which exerts the strongest influence on remotely sensed data is topography (Estes 1983, p.962). In montane regions, changing slope and aspect angles produce a phenomenon known as 'anisotropic reflectance' (Hugli and Frei 1983). The reflectance of a single cover type varies with topography, and therefore, the classification process for rugged terrain is seriously impaired (Smith et al. 1980).

These radiometric effects are very complex for vegetated surfaces, and under many sensing conditions modelling this differential reflectance may be limited (Hugli and Frei 1983). Three techniques which have been applied to reducing the topographic effect are spectral-band ratioing, application of a Lambertian model and application of a non-Lambertian model. This paper will explore the use of the latter two techniques to correct for uneven reflectance patterns in Thematic Mapper imagery. To our knowledge, this study involves the first application of the Lambertian and non-Lambertian models to correct for anisotropic reflectance in the tropics.

In this article, we will describe several approaches to mapping land cover in tropical montane areas using TM imagery. The research was conducted in selected areas of both Costa Rica and Ecuador that include very rugged terrain and a variety of land cover types. The sites differ considerably with respect to the number of cover types and the spatial heterogeneity of the landscape. Whereas the Costa Rican site includes forest, urban areas and well-established agricultural areas, the Ecuadorian site includes land within and adjacent to a national park that has been modified by recent cutting and burning. Therefore, the Costa Rican site exhibits a higher number of cover types and more discrete boundaries between cover types than does the Ecuadorian site. Our purpose is to demonstrate that topographic normalization techniques are applicable to remote sensing projects in diverse tropical montane areas.

First, we will describe several pre-processing techniques that were employed to reduce anisotropic reflectance in images covering mountainous terrain. Second, we will describe image processing techniques used for discriminating among several important cover types in both study areas. Finally, we discuss the potential for topographic normalization models to improve classification accuracies in the tropics through general comparison of the results from the two study areas. 


\section{Background: topographic normalization}

In mountainous terrain, slope and aspect vary significantly over short distances, so that a wide range of effective view and illumination angles can be obtained for a single Landsat scene (Smith et al. 1980). This differential illumination of surfaces manifests visually as the impression of relief, and is referred to as the 'topographic effect' (Holben and Justice 1979). Formally defined, it is the variation in radiances from inclined surfaces as compared to the spectral response from a horizontal surface as a function of the orientation of the surfaces relative to the light source (incidence angle) and sensor position (exitance angle) (Holben and Justice 1979, Justice et al. 1980).

Land cover classification with multispectral data in mountainous terrain is often unsuccessful because surfaces of the same cover type but with different slope angles and aspects reflect different radiance values (Holben and Justice 1979). The effect has been seen to vary considerably with small changes in solar elevation and azimuth, and slope angle. Various efforts have been made to minimize this topographic effect, and in some instances, to provide accessible topographic normalization routines (Holben and Justice 1979, Justice and Holben 1979, Justice et al. 1980, Smith et al. 1980, Teillet et al. 1982, Estes 1983, Hugli and Frei 1983, Kowalick et al. 1983, Stohr and West 1985, Hall-Konyves 1987, Kawata et al. 1988, Leprieur et al. 1988, Civco 1989, Colby 1991, Meyer et al. 1993, Hodgson and Shelley 1994, Ekstrand 1996).

The simplest technique for reducing anisotropic reflectance imposed by topographic effects, shadows and seasonal changes in solar illumination is the band ratio transformation (Jensen 1996, Crippen 1988). Dividing spectral values from one band by those of another produces a data layer that may enable one to distinguish among different cover types more accurately than with the original data set. One problem with this technique, however, is that variations in the albedos of surface covers may be obscured if they have similar spectral reflectance properties (Sabins 1997).

Two important models have been applied in previous topographic normalization efforts. The first, a Lambertian model, assumes that phenomena on the surface of the earth reflect incident radiation in all directions equally. A good approximation would be a piece of white matte paper illuminated by diffuse skylight; the perceived brightness of the paper does not change with angle of view (Simonett 1983). According to Smith et al. (1980) the radiance of a Lambertian surface is given by:

$$
L(\lambda, e)=L_{n}(\lambda) \cos i
$$

where: $L=$ radiance, $\lambda=$ spectral wavelength, $e=$ exitance angle $=$ slope, $L_{n}=$ radiance when $i=e=0, i=$ incidence angle.

Previous studies have reported that topographic normalization efforts based on the Lambertian model may be valid only for a restricted range of incident and exitant angles (Smith et al. 1980). Moreover, it may overcompensate for the 'topographic effect' (Justice and Holben 1979, Estes 1983, Colby 1991, Ekstrand 1996).

A non-Lambertian model assumes that incident radiation is scattered according to the bidirectional reflection distribution function (BRDF) of illuminated phenomena (Estes 1983), which is related to surface roughness (Smith et al. 1980). In previous studies the non-Lambertian assumption has been more effective than the Lambertian assumption in representing vegetated surfaces (e.g. Smith et al. 1980, Colby 1991). The BRDF can be described by the Minnaert constant $k$, which was first applied by Minnaert (1941) in photometric analysis of lunar surfaces. Although the diffused 
light component has been neglected in previous studies (e.g. Smith et al. 1980, Colby 1991), removal of atmospheric path radiance should be considered.

To derive the Minnaert constant $k$, the following equation, which provides the satellite radiance, is first linearized (Smith et al. 1980):

$$
L(\lambda, e)=L_{n}(\lambda) \cos ^{k(\lambda)-1} e
$$

The regression value for $k$ is then obtained using:

$$
L \cos e=L_{n} \cos ^{k} i \cos ^{k} e
$$

and

$$
\log (L \cos e)=\log L_{n}+k \log (\cos i \cos e)
$$

where: $y=\log (L \cos e)$, the response variable, $x=\log (\cos i \cos e)$, the independent variable, $b=\log \left(L_{n}\right)$ to obtain the linear form $y=k x+b$. The equation is solved for $k$, which is the slope of the regression line and the Minnaert constant. A range of incident and exitant angles is required to accurately calculate the Minnaert constant $k$.

A backwards radiance correction transformation can be developed using both the Lambertian and non-Lambertian assumptions if data for $L_{n}$ are not available (Smith et al. 1980). For the Lambertian assumption and equation (1):

$$
L_{n}=L / \cos i
$$

For the non-Lambertian assumption and equation (2):

$$
L_{n}=L(\cos e) /\left(\cos ^{k} i \cos ^{k} e\right)
$$

The effective incidence angle, cosine $i$, measured from the surface normal is defined by (Hodgson and Shelley 1994):

$$
\cos i=\cos \left(90-\theta_{s}\right) \cos \theta_{n}+\sin \left(90-\theta_{s}\right) \sin \theta_{n} \cos \left(\phi_{s}-\phi_{n}\right)
$$

where: $\theta_{s}=$ solar elevation angle, $\theta_{n}=$ surface normal zenith angle or slope of the terrain surface, $\phi_{s}=$ solar azimuth angle, $\phi_{n}=$ surface azimuth or aspect angle.

The effectiveness of utilizing the Minnaert constant in the topographic normalization process is a function of numerous variables, many of which have not been quantified. Some papers have investigated the application of detailed a priori knowledge of site characteristics (i.e. Ekstrand 1996) to correct for anisotropic reflectance utilizing the Minnaert constant. This paper, as suggested by Estes (1983, p. 1059), continues attempts (e.g. Colby 1991, ERDAS 1994, Hodgson and Shelley 1994, Colby 1995, Keating 1995) to develop reliable image preprocessing methods for reducing topographic effects, without detailed a priori knowledge of surface feature reflectance values, for land cover classification. Whereas attempts to reduce topographic effects in Landsat TM imagery utilizing the Minnaert constant have been undertaken in temperate regions, this paper will describe the first application of these techniques in the Neotropics (Colby 1995, Keating 1995).

\section{Study area descriptions}

\subsection{Ecuador}

Podocarpus National Park, the southernmost protected area in Ecuador (figure 1), covers more than 146000 ha of montane forest and páramo (alpine tundra) communities. Located on the eastern cordillera of the Ecuadorian Andes, this region 


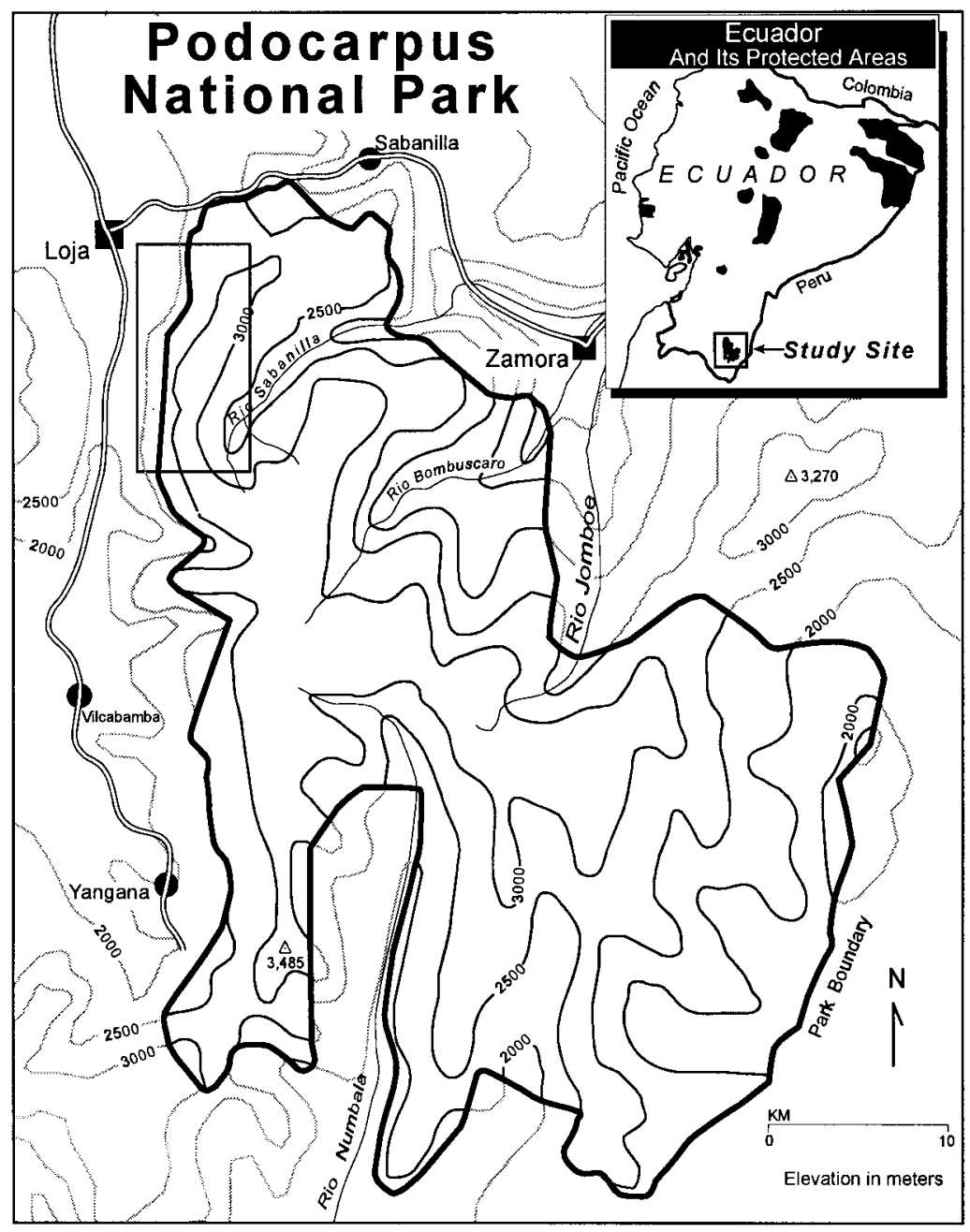

Figure 1. Map of Podocarpus National Park, Ecuador. The study site is indicated with a rectangular box in the northwestern section of the park.

includes a number of low, rugged mountain ranges that may extend for more than $50 \mathrm{~km}$. These mountains are not of volcanic origin, and glaciers have not been present since the Pleistocene (see Hastenrath 1981). The physiography of the study area is characterized by a series of sharp ridges, the slopes of which are dissected by numerous streams. Because these highlands receive more than $4000 \mathrm{~mm}$ of rain each year (Keating 1995), rates of erosion and mass wasting are high.

The study area includes northwestern Podocarpus National Park and adjacent sections of the Loja Province (figure 1). An $8000 \mathrm{~m} \times 13500 \mathrm{~m}\left(108 \mathrm{~km}^{2}\right)$ area was chosen that includes a diverse set of terrain features and cover types. Elevation ranges from $3432 \mathrm{~m}$ at the highest point of the Cordillera Oriental down to $2120 \mathrm{~m}$ near the western highway. This region is characterized by numerous 'knife-edged' ridges, and slope angles vary from $0^{\circ}$ to $57^{\circ}$, where the mean is $25^{\circ}$ and the standard deviation is $16^{\circ}$ (Keating 1995). 
This area was chosen because it includes a diverse array of vegetation communities and land uses. Both grass and shrub páramo communities dominate the upper sections of the Cordillera Oriental and the adjacent ridge tops above $3100 \mathrm{~m}$. Because several areas of the ridge top have been burned at least once since 1983, the vegetation varies tremendously in structure and composition. The upper montane forests $(>2600 \mathrm{~m})$ in this region have not experienced many anthropogenic disturbances during the past 25 years.

Below $2600 \mathrm{~m}$ elevation, most areas have been disturbed repeatedly by humans during the past four decades. Logging, highway construction and the gradual expansion of agricultural areas have resulted in nearly complete deforestation of the entire Loja Province (Fundación Natura 1992). Many farms, pastures and small villages currently cover much of the land adjacent to the western edge of the Park. Moreover, there are also many abandoned, degraded lands in this zone, which are usually covered by some form of scrub vegetation. Many hillsides above the agricultural areas are burned every several years, as fires are often associated with human activities in the area. Therefore, the western section of the study area is covered with a very patchy mosaic of plant communities that exhibit various stages of recovery after disturbances.

\subsection{Costa Rica}

The Navarro watershed is located at the headwaters of the Reventazón river basin in Costa Rica (figure 2). The watershed is an important source of natural resources within the country. For example, the hydropower potential of the Reventazón river basin may be unsurpassed in Costa Rica (Quesada 1979). High sediment loads and streamflow variability from the Navarro watershed affect the proximate Cachi reservoir (Quesada 1979, Jansson and Rodriguez 1992) and planned hydroelectric projects further downstream.

The elevation of the $279 \mathrm{~km}^{2}$ Navarro watershed ranges from approximately $3300 \mathrm{~m}$ near the summit of the Irazú volcano to $1029 \mathrm{~m}$ at the La Troya streamflow gauge. Slope angles calculated for the watershed varied from $0^{\circ}$ to $48^{\circ}$, with a mean of $19^{\circ}$ and standard deviation of $13^{\circ}$ (Colby 1995). In the north the watershed drains the southern slope of the Irazú volcano, which is an important agricultural area for the country (Cortés and Oconitrillo 1987).

The central section is the most level and contains the city of Cartago. The Navarro River flows through the mountainous southern section, which is covered primarily by premontane moist and wet forests (Tosi 1969, Holdridge 1967). Despite the protected status of the forests, this area has experienced considerable modification by human activity.

Natural hazards have also shaped the terrain surface of the Navarro watershed. Recurrent hazards include, volcanic eruptions and debris flows (Waldron 1967), floods (Solis et al. 1991), landslides (Mora 1987), and seismic activity. Deforestation has also contributed to flooding in the watershed (Quesada 1979).

\section{Methodology}

4.1. $D E M$

\subsubsection{Ecuador}

Before topographic normalization was performed, a digital elevation model (DEM) was constructed with the use of several software packages. Initially, sections of a 1:50000 scale topographic map (40 m contour interval) were digitized with 


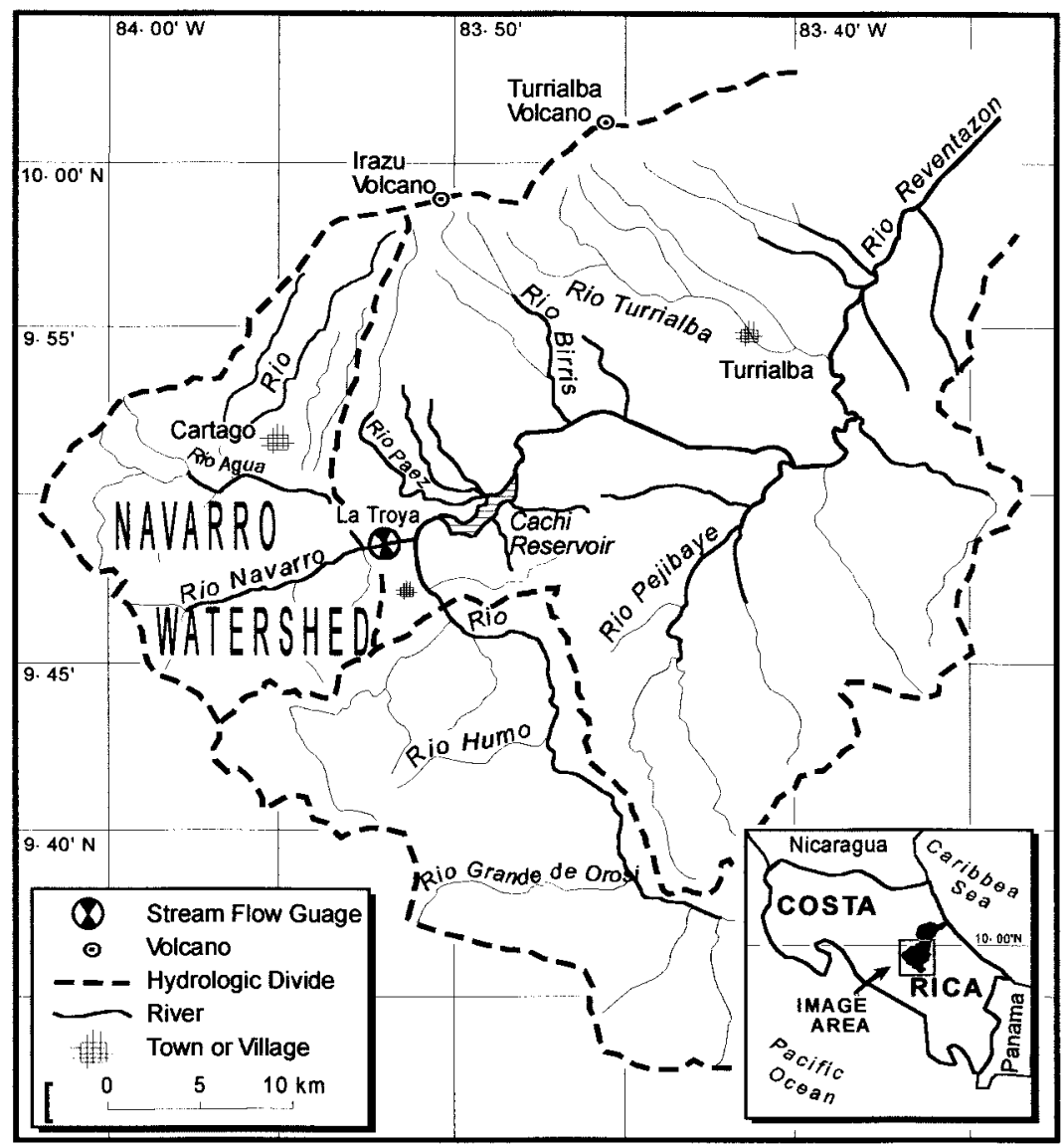

Figure 2. Map of Reventazon River Basin, Costa Rica.

AutoCAD software (Autodesk 1992). All index contour lines were digitized, and other contour lines were added for areas above $3200 \mathrm{~m}$ and for those characterized by steep slopes. Before a DXF output file was created, isolines were given elevation labels and placed within a common layer.

ARC/INFO software (ESRI 1992) was utilized to create a lattice from the DXF file. After an ARC coverage was created, the ARCTIN module was used to build a triangulated Irregular Network (TIN), and the TINLATTICE program was used to convert the TIN to a lattice. Upper left and lower right corner coordinates were selected that matched those of the study area. The resulting lattice was then exported to ERDAS IMAGINE 8.1 (ERDAS 1994). The image file was filtered once with a $5 \times 5$ pixel low pass filter to ensure that the digital model did not contain areas of unnaturally abrupt changes in slope (figure 3 ).

\subsubsection{Costa Rica}

The primary elevation data used to create a DEM for the Navarro watershed was the US Defense Mapping Agency's (DMA) digital terrain elevation data (DTED). DTED are distributed in 1 degree by 1 degree or smaller cells, with a 16-bit range of elevation values. In this study, two cells of DTED Level 1 data were 


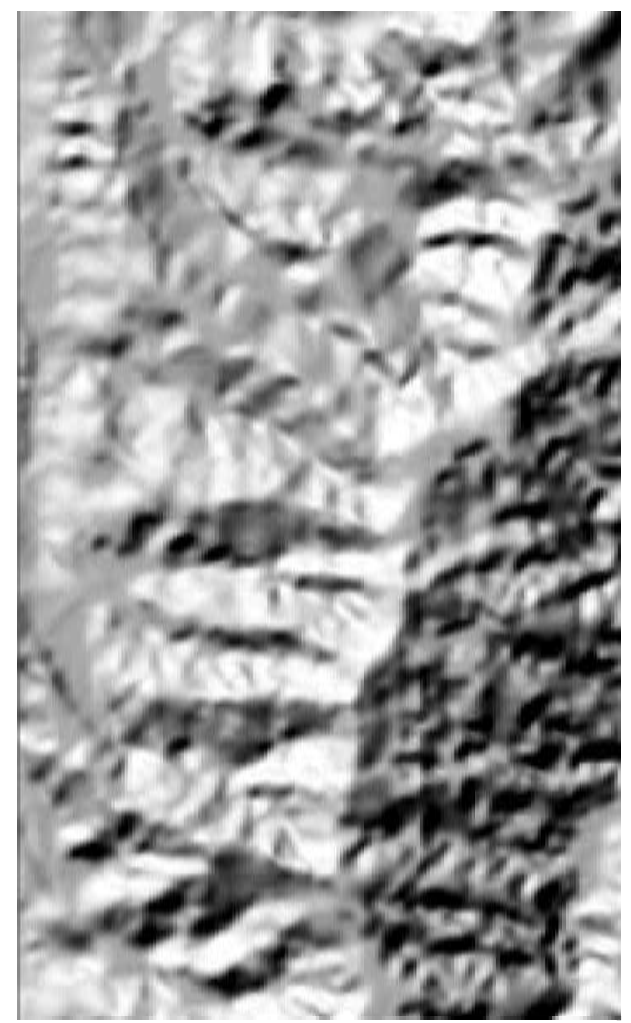

Figure 3. Shaded relief image of Podocarpus National Park.

utilized. The cell boundaries extended from $9^{\circ} \mathrm{N}$ to $10^{\circ} \mathrm{N}$ and from $-83^{\circ} \mathrm{W}$ to $-85^{\circ} \mathrm{W}$. The data were provided in a $3 \mathrm{arc} \mathrm{s}^{-1}$ format, and the original resolution of the data between $9^{\circ} \mathrm{N}$ and $10^{\circ} \mathrm{N}$ latitude was $92 \cdot 161 \mathrm{~m}^{2}$. A projection file was created in ARC/INFO to enable rectification of the original points from a geographic to a Lambert Conformal Conic projection. To enable integration with additional data sets, the DTED file was resampled to $90 \mathrm{~m}$ with a bilinear interpolation routine (figure 4).

\subsection{Image preprocessing}

Before land cover classification for each study area was undertaken, three preprocessing steps were carried out: haze removal, rectification, and topographic normalization.

\subsubsection{Ecuador}

This study involved a cloud-free $15 \times 15 \mathrm{~km}$ TM subscene, which was located in Path 10, Row 63, and acquired on 2 November 1989. Bands 1-5 and 7 were utilized for an $8 \mathrm{~km} \times 13.5 \mathrm{~km}$ section of this scene. After the image was checked for radiometric distortions, such as line striping, minimum value subtraction was performed to remove the effects of atmospheric scattering (Jensen 1996). Histograms for individual bands showing numbers of pixels per digital number did not reveal any low outliers. Therefore, an atmospheric correction program was used to subtract the lowest digital number of a given band from each pixel in the band. 


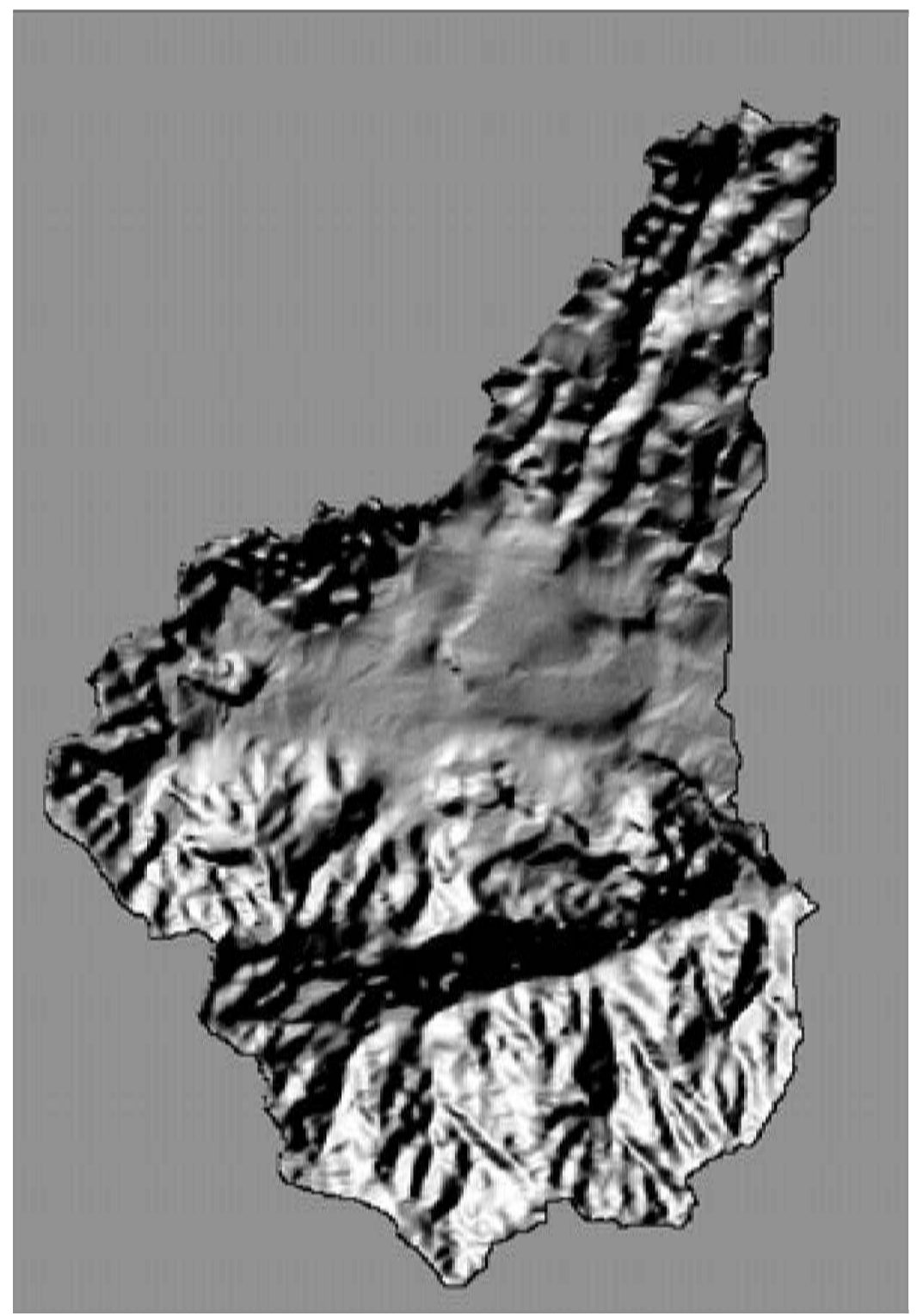

Figure 4. Shaded relief image of Navarro Watershed.

Using ERDAS software, the TM image was rectified using known ground-control points from the topographic map mentioned above. Twenty points were utilized, and a root mean squared error (R MSE) of 0.388 was achieved. During the resampling process, the image was subset to precise UTM coordinates (Zone $17 \mathrm{~S}$ ); a nearest neighbour interpolation procedure determined spectral values for each pixel. The image extends from 700000 to 708000 m East, and 9543000 to $9556500 \mathrm{~m}$ North.

\subsubsection{Costa Rica}

For the Costa Rican study site the primary source for land cover information was a Landsat TM digital image acquired on 19 February 1986. The Navarro watershed was located in Quad 4 of the Landsat scene at Path 15, Row 53. 
A haze removal technique to reduce the increase in overall brightness in each image due to atmospheric scattering was completed after identifying the shift from zero in the histogram for each band (Richards 1986). A rectification process was then performed to register and resample the image to a Lambert Conic Conformal projection. An RMSE of $0 \cdot 110$ was obtained using 14 ground control points. A nearest neighbour interpolation procedure provided spectral values for the rectified cells, which were resampled to $90 \mathrm{~m}$ to match the resolution of the DEM.

\subsubsection{Topographic normalization}

A topographic normalization routine based on the Lambertian model was developed for the 8.1 version of ERDAS IMAGINE. Hodgson and Shelley (1994) also developed an IMAGINE Model Maker algorithm based on the non-Lambertian model. This algorithm allows for the inclusion of unique Minnaert constants for each spectral band; however, the constants themselves must be calculated separately. For these studies, a flexible method for deriving the Minnaert constants was developed using IDRISI, a raster-based GIS package for the personal computer (Eastman 1993), and an additional program for calculating logarithms.

The images were first normalized using the Lambertian model. The topographic normalization routine in IMAGINE was utilized for this process. In addition to the DEM and TM images, the IMAGINE algorithm required the solar azimuth (Ecuador $109 \cdot 5^{\circ}$, Costa Rica $124^{\circ}$ ) and solar elevation angle (Ecuador $51 \cdot 2^{\circ}$, Costa Rica $45^{\circ}$ ) for each satellite image.

To normalize the images using the non-Lambertian assumption, an algorithm similar to that developed by Hodgson and Shelley (1994) was operated in IMAGINE. This algorithm allows the creation of image layers consisting of the cosine of the incidence angle $(\cos i)$ and cosine of the exitance angle $(\cos e)$ for each cell. After cosine files were created, they were imported into IDRISI along with the TM image as separate bands images. The Overlay module in IDRISI was then used to multiply the cosine layers together. The TM band images were then multiplied by the ' $\cos e$ ' image separately. Logarithms for the resulting images were calculated in a separate $\mathrm{C}++$ program and re-imported into IDRISI.

The Regress module in IDRISI calculated the linear regression between the independent variable image and the dependent variable images equation (4). The Minnaert constant for each spectral band was the slope of the regression line. The Regress module also provides the capability to use a mask to highlight the area from which to calculate the regression. For example, a mask was used to calculate Minnaert constants solely for the area representing the Navarro watershed. The derived Minnaert constants (table 1) were then used as parameters to normalize

Table 1. Minnaert constants derived for the non-Lambertian corrected images.

\begin{tabular}{lcc}
\hline TM band & Ecuador & Costa Rica \\
\hline 1 & $0 \cdot 326$ & $0 \cdot 780$ \\
2 & $0 \cdot 414$ & $0 \cdot 757$ \\
3 & $0 \cdot 433$ & $1 \cdot 019$ \\
4 & 0.421 & $0 \cdot 288$ \\
5 & 0.528 & $0 \cdot 743$ \\
7 & 0.521 & NA \\
\hline
\end{tabular}


the images using an algorithm similar to that developed by Hodgson and Shelley (1994) and the non-Lambertian assumption.

\subsection{Image classification}

Both studies utilized training site development and image classification capabilities available in IMAGINE. Training sites for both study areas were chosen based upon personal site visits, aerial photography, and for the Costa Rican watershed, land use maps. After these sites were selected, histograms and training site statistics were displayed using a signature editor. We determined whether or not training site statistics were parametric, and developed a covariance matrix to classify the image with parametric decision rules.

In order to evaluate the spectral separation of training site samples, a number of methods were utilized in an iterative fashion to provide a basis for deciding whether to retain, merge, reshape, or find new training sites. Initially, mean values of training site samples were displayed with rectangular or elliptic boundaries on scatter plots of spectral band combinations. We also utilized statistical estimates of separability and contingency. In particular, we examined the divergence values generated by the Jeffries-Matusita algorithm, which has been shown to be very effective in other studies (e.g. Mausel et al. 1990). 'Divergence' is a measure of statistical separability between two groups or classes (Toll 1984) and serves as an indirect measurement of classification accuracy.

Scene classification for both study areas was undertaken using a decision rule which first applied a parallelepiped classification, and then classifies the remaining pixels using a maximum likelihood classifier. In addition, a minimum distance classifier performed well for the Ecuadorian study area. Both studies employed a 'post classification sort' (Hutchinson 1982) before accuracy assessments were performed.

\subsubsection{Ecuador}

While the two studies shared a similar classification methodology, their classification categories differed significantly. In the Ecuadorian study, initial classification categories included grass páramo, shrub páramo, forest, and lower elevation 'deforested areas', which consisted of pastures, abandoned pastures and immature secondary forest. Because it was not possible to discriminate effectively among these latter categories, they were combined into a 'deforested' category.

Before accuracy assessments were conducted, two procedures were employed to reduce the variance in the classified images. Because the minimum mapping unit in the ground truth map was $3 \mathrm{~mm}$, or 150 ground metres, a $3 \times 3$ majority filter was used to remove small, homogeneous clusters of pixels. This procedure ensures that spatial variation in the classified image is not significantly higher than that in the ground reference image.

Secondly, postclassification sorting (e.g. Hutchinson 1982) was performed to reduce misclassification of different cover classes derived from very similar spectral signatures. With this technique, decision rules involving ancillary data layers are used to separate classes with different geographical positions but similar training signatures. In this study, all páramo areas that occurred below $2800 \mathrm{~m}$ elevation were reclassified as 'deforestation', and all deforested areas that occurred above $2800 \mathrm{~m}$ were reclassified as páramo. 


\subsubsection{Costa Rica}

Remotely sensed digital satellite imagery was utilized by Colby (1995) to provide land cover classifications in order to characterize the Navarro watershed for hydrologic modelling purposes. Classification schemes used as reference included an adaptation of the Anderson Classification System (Anderson et al. 1976) for Costa Rica made by Campbell et al. (1980), and categories from 1:10 000 scale land use maps which covered a portion of the watershed. Areas used as training sites were selected based on information from site visits, aerial photographs, and the land use maps. Initial training sites were identified on the $30 \mathrm{~m}$ TM image, and then used to guide the selection of training sites on the $90 \mathrm{~m}$ TM image.

Three images were classified using a 12 category classification scheme: the unnormalized image, the image normalized using a Lambertian assumption, and the image normalized using a non-Lambertian assumption. It was not possible to achieve spectral separation between forests and some fields of coffee. Therefore, a post-classification sort (Hutchinson 1982) was undertaken to reclassify several coffee fields, to the west and south of Cartago, from forest. The 12 classification categories consisted of:

(1) Bare areas 1 -wet soil, agricultural fields

(2) Bare areas 2 - exposed rock, stripmines or quarries

(3) Grass 1-dominantly dry grass

(4) Grass 2-lush-growing, green grass

(5) Grass 3-dry grass with brush component, charall

(6) Coffee

(7) Crops

(8) Brush

(9) Forest

(10) Urban

(11) Residential

(12) Invernadernos (greenhouses)

After the initial classification, the 12 categories were collapsed or grouped into 5 more general categories for hydrologic purposes (table 2). Accuracy assessment was performed on the images consisting of the 5 general categories:

(1) Bare areas,

(2) Grass,

(3) Shrubs,

(4) Forest, and

(5) Impervious areas.

Table 2. Hydrologic categories and sub-categories for the Costa Rican study.

\begin{tabular}{lllll}
\hline Bare & Grass & Shrubs & Forest & Impervious \\
\hline bare 1 & grass 1 & coffee & forest & urban \\
bare 2 & grass 2 & crops & & $\begin{array}{l}\text { residential } \\
\text { invernaderos }\end{array}$ \\
& grass 3 & brush & & invernad \\
\hline
\end{tabular}




\subsection{Accuracy assessment}

\subsubsection{Ecuador}

Initially, classified images were evaluated visually, and the effects of topographic normalization were noted. All three images were also evaluated quantitatively with the use of a digital ground truth map. Several types of ground reference data (sensu Congalton 1988) were included in the ground-truth map. Initially, aerial photographs of scale 1:60 000 were interpreted for both 1976 and 1989. Polygons were transferred manually to a topographic map, which were later digitized in AutoCAD. Image files containing the polygons were created in ERDAS 7.5 with a grid-to-polygon program.

Between September 1991 and July 1992, extensive field reconnaissance trips were made throughout the study site. Numerous $35 \mathrm{~mm}$ photographs were taken of locations that could be identified on topographic maps. Vegetation composition and structure were noted, and many zones of anthropogenic disturbance were mapped in the field. These maps were compiled, and polygons of homogeneous cover types were digitized.

These digital cover maps were transferred to IDRISI. Data layers were iteratively combined to produce a master cover map for the study areas. The Errmat module of IDRISI was then used to perform the accuracy assessments. In accordance with a formula developed by Fitzpatrick-Lins (1980), 1000 pixels were randomly selected for the assessment of TM images. Individual pixels for each category in the classified images were compared to the ground truth map.

For each classified image, an error matrix was developed, and 'overall accuracy' was calculated (Story and Congalton 1986). Kappa statistics, which assess overall accuracy by incorporating individual errors of omission and commission, were also calculated (Congalton 1991). For both study areas, the KAPPA program (Congalton 1991 ) was used to compare Kappa statistics derived from classified images that had received different normalization treatments.

\subsubsection{Costa Rica}

For the five land cover categories in this assessment 257 samples were randomly generated. In previous research a standard random sampling approach has been determined to provide satisfactory results for classification evaluation (Congalton 1988 ).

The following process was developed to evaluate each sample pixel. The pixel was first located on the $30 \mathrm{~m} \mathrm{TM}$ image, and an initial assessment was made as to the location and general pattern of surrounding land cover types. If located in the northern half of the watershed, the pixel would be identified on the 1:10000 scale land use maps. Black and white stereo pair aerial photographs (1:20000 scale) were also analysed, for example, to identify seasonal land cover types such as crops. If located in the southern half of the watershed, black and white stereo pair aerial photographs (1:60000 scale) were analysed to identify the reference pixel. If a land cover change had occurred in the area of a sample pixel location, which did not occur often, the sample pixel was discarded.

Rather than using techniques such as the majority value for a $3 \times 3$ window, the actual value of the sample pixel was used for evaluation purposes. It was believed that an averaged value from a $3 \times 3$ window would not accurately represent the heterogeneity of certain cover types, such as agricultural areas, at the $90 \mathrm{~m}$ resolution. To ensure identification accuracy, the classification process for each reference pixel was carried out twice. The IDRISI module Errmat was used to derive error matrices and Kappa coefficients (Rosenfield and Fitzpatrick-Lins 1986). 


\section{Results}

Minnaert constants differed substantially between the two study sites (table 1). For the Ecuadorian site, Minnaert constants are typically higher for bands that correspond to longer wavelengths; there was a slight decrease between bands 5 and 7, which represent mid-infrared bands. In the Costa Rican scene, the greatest range of difference was between bands 3 and 4 . The constants were typically higher and more homogeneous in the Costa Rican subscene than in the Ecuadorian one. The larger spatial extent of the study area, and aggregation of the TM image from 30 to $90 \mathrm{~m}$ could have contributed to the derivation of more homogeneous Minnaert constants for the Costa Rican site.

For both study sites, uncorrected images are considerably different than their corresponding non-Lambertian-corrected images (figures 5-8). A reduction of the topographic effect is visually apparent in the non-Lambertian normalized images: whereas effects of anisotropic reflectance, such as topographic inversion and shadows, are apparent in the uncorrected images, they are nearly absent in the non-Lambertiancorrected images. The non-Lambertian-corrected images exhibit far fewer effects of aspect and illumination angle than do the corresponding uncorrected images.

A reduction of the topographic effect was less visually apparent in the Lambertiannormalized images, especially in the Ecuadorian image. In fact, pixels that cover areas of high slope appear over-corrected, so that some pixels appear much brighter than they normally would in the uncorrected images. Therefore, sections of the study sites that occur in steep areas appear 'washed-out', and classification of these sections of the images was not particularly successful.

Quantitative assessments of classification accuracies agree with the visual assessments (tables 3 and 4). For the Ecuadorian study area, overall accuracies ranged from 65.07 (Lambertian corrected, minimum distance classification) to 79.69 percent (non-Lambertian, minimum distance classification). The results from the Costa Rican watershed ranged from 76.65 (Lambertian corrected, maximum likelihood classification) to $81 \cdot 1$ percent (non-Lambertian, maximum likelihood classification). For both study areas, therefore, classification accuracies were lowest for Lambertian-corrected images and highest for non-Lambertian-corrected images.

Table 3. Results of the accuracy assessments for Ecuador.

\begin{tabular}{llcc}
\hline Correction type & Classification algorithm & Overall accuracy $(\%)$ & Kappa statistics $(\%)$ \\
\hline Uncorrected & maximum likelihood & 75.98 & $48 \cdot 32$ \\
Uncorrected & minimum distance & $77 \cdot 18$ & 53.94 \\
Lambertian & maximum likelihood & 75.38 & 54.59 \\
Lambertian & minimum distance & 65.07 & 44.42 \\
Non-Lambertian & maximum likelihood & $77 \cdot 88$ & $55 \cdot 78$ \\
Non-Lambertian & minimum distance & 79.69 & 61.50 \\
\hline
\end{tabular}

Table 4. Results of the accuracy assessments for Costa Rica.

\begin{tabular}{llll} 
Correction type & Classification algorithm & Overall accuracy $(\%)$ & Kappa statistics \\
\hline
\end{tabular}

Uncorrected

Lambertian

maximum likelihood

$77 \cdot 82$

$67 \cdot 86$

Non-Lambertian

maximum likelihood

$76 \cdot 65$

$66 \cdot 03$

maximum likelihood

$82 \cdot 10$

$74 \cdot 10$ 

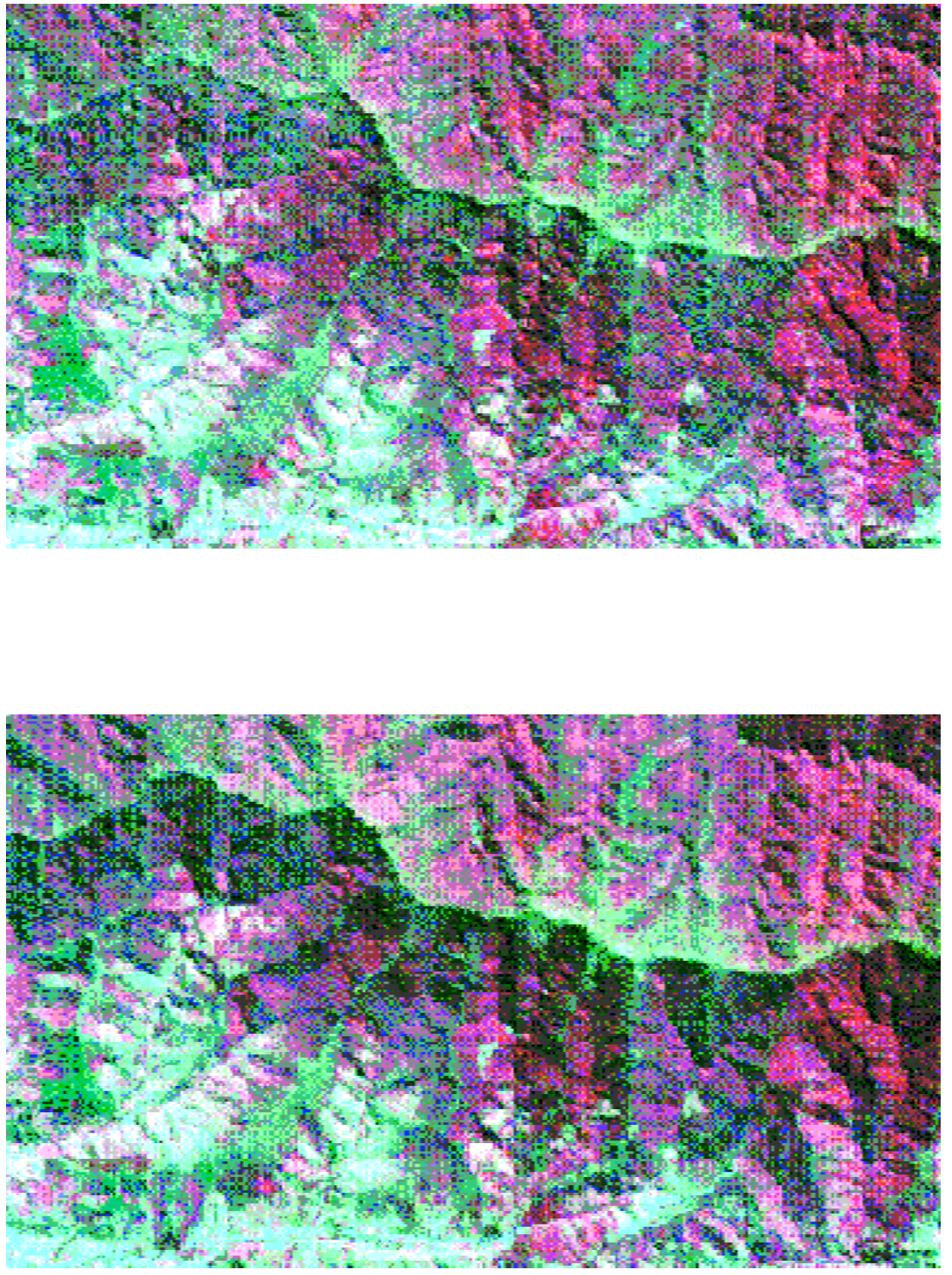

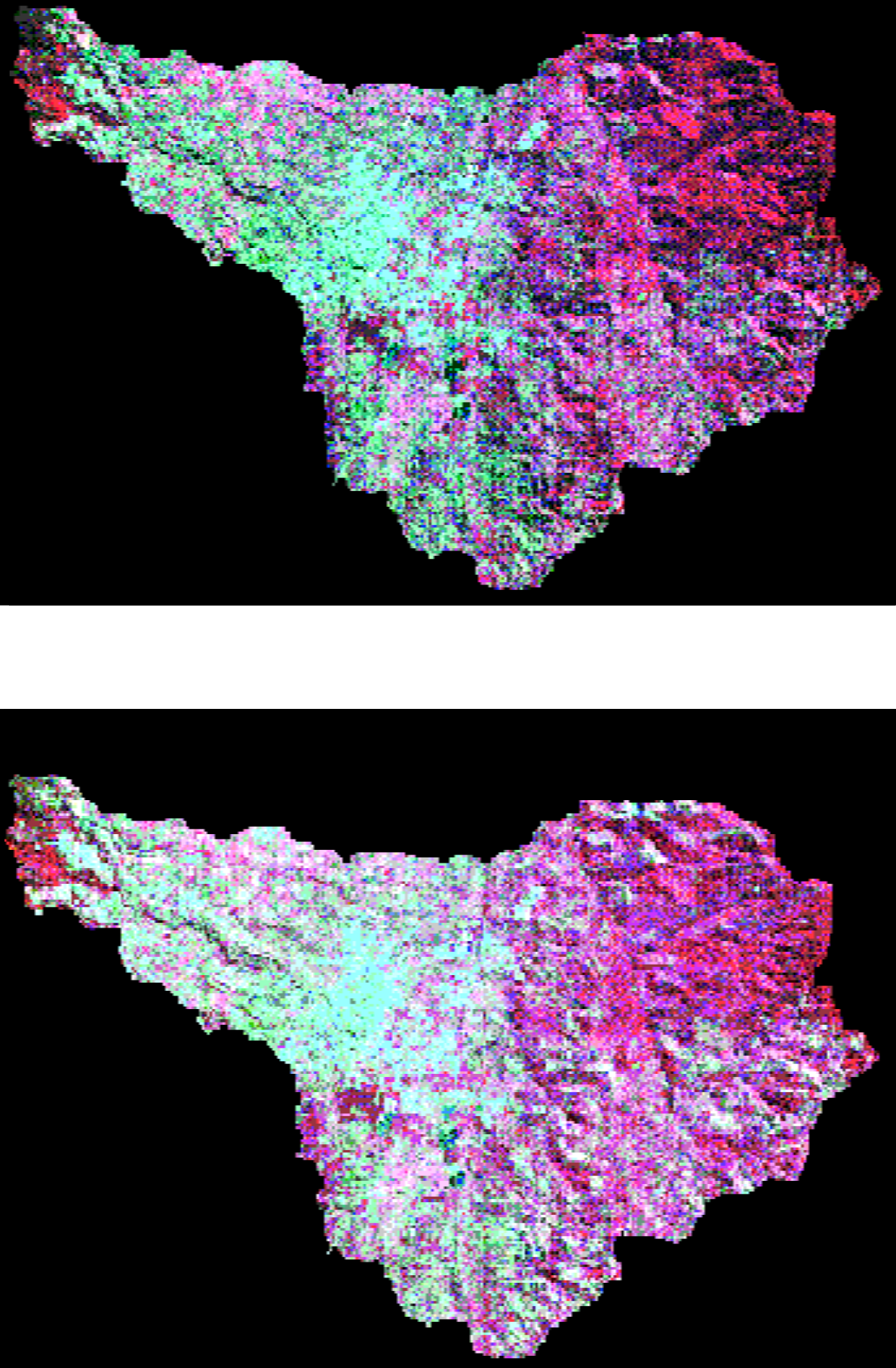
The Kappa statistics, which incorporate errors of omission and commission, were somewhat lower than the 'overall' accuracy ratings mentioned above (tables 3 and 4). However, the range of Kappa statistics is greater than that achieved with the overall percentages. The KAPPA program indicated that for the Costa Rican site, Kappa statistics were significantly different between the Lambertian-corrected and non-Lambertian corrected images (table 5). However, there were not significant differences between other combinations of images.

For the Ecuadorian site, there were significant differences between nearly all pairs of Kappa statistics calculated (table 6). For images classified with the Maximum Likelihood classifier, only the F-statistic calculated for the Lambertian and nonLambertian corrected images was insignificant. In contrast, for the images classified with the Minimum Distance algorithm, all F-statistics were significant $(p<0.05)$; the non-Lambertian image is clearly the most accurate, while the Lambertian image is least accurate. Collectively, these assessments suggest that better separation of categories was achieved with the non-Lambertian correction method.

\section{Discussion}

Overall, results for both study areas indicated that the non-Lambertian-corrected images were the most accurate. This agreement is significant given the potential sources of error inherent in evaluating the effectiveness of topographic normalization routines through conventional accuracy assessments, and given that two different techniques were utilized for dissimilar study areas. Because it is difficult to assess accuracy with ground reference data, the Kappa statistics and overall percentages were believed to underestimate the true value of topographic normalization.

Table 5. Results of the KAPPA analysis test for comparison between error matrices for the Costa Rican study site.

\begin{tabular}{lcc}
\hline Topographic normalization treatment & F statistic & Result $^{\mathrm{a}}$ \\
\hline Uncorrected vs Lambertian-corrected & 0.35 & $\mathrm{NS}$ \\
Uncorrected vs non-Lambertian-corrected & 1.23 & $\mathrm{NS}$ \\
Lambertian-corrected vs non-Lambertian corrected & 1.59 & $\mathrm{~S}^{\mathrm{b}}$ \\
\hline
\end{tabular}

\footnotetext{
${ }^{\mathrm{a}} \mathrm{S}=$ significant, $\mathrm{NS}=$ not significant

${ }^{\mathrm{b}} \alpha=0.05$.
}

Table 6. Results of the KAPPA analysis test for comparison between error matrices for the Ecuadorian study site.

Topographic normalization treatment

F statistic

Result $^{\mathrm{a}}$

A. Maximum Likelihood Classifier

Uncorrected vs Lambertian-corrected

Uncorrected vs non-Lambertian-corrected

Lambertian-corrected vs non-Lambertian corrected

$0 \cdot 33$

$S^{b}$

B. Minimum Distance Classifier

Uncorrected vs Lambertian-corrected

Uncorrected vs non-Lambertian-corrected

Lambertian-corrected vs non-Lambertian corrected

$2 \cdot 65$

$1 \cdot 22$

$4 \cdot 99$

$S^{b}$
$S^{b}$
$N S$
$S^{b}$
$S^{b}$
$S^{b}$

${ }_{\mathrm{b}}^{\mathrm{a}} \mathrm{S}=$ significant, $\mathrm{NS}=$ not significant.

${ }^{\mathrm{b}} \alpha=0.05$. 
In the Ecuadorian study site, the heterogeneity of vegetation communities below $2600 \mathrm{~m}$ was very high due to the complex disturbance history of this region; that portion of the landscape is covered with a patchy mosaic of plant communities that exhibit various stages of recovery after cutting and burning. Because several of the categories classified may occur within a relatively small area, the mixed pixel effect (e.g. Vanclay and Preston 1990) precluded more accurate classification of the lower landscape.

Secondly, whereas most of the steepest slopes are covered with forests, the sections of the study area that exhibit the greatest heterogeneity of land cover are located on relatively gentle slopes; both the forest/deforestation ecotone and the páramo communities are located on slopes of less than $20^{\circ}$ and in well illuminated areas. Had the areas of greatest spatial heterogeneity of cover types been located on steeper slopes, the effects of topographic normalization would have been even more apparent.

In the Costa Rican watershed, the effects of resampling the original $30 \mathrm{~m}$ TM data to $90 \mathrm{~m}$ on classification accuracy is unclear. Markham and Townshend (1981) found that scene noise tends to be averaged out at lower resolutions. The percentage of boundary (mixed) pixels increases as spatial resolution decreases, however, and this tends to decrease classification accuracies.

The drainage pattern on the slopes of the Irazú volcano was likely altered during the last eruption (March 1963-March 1965). Additionally, emergency measures such as channel improvements and levees were undertaken (Waldron 1967). Alterations to the terrain in the watershed may not have been incorporated in the creation of the DEM for this watershed, which is supported by misalignment of drainage patterns between the DEM and TM imagery in some areas (Colby 1995). Moreover, the relatively coarse resolution $(90 \mathrm{~m})$ of the DEM may have hindered normalization effectiveness; use of a higher quality DEM would likely increase the accuracy of the normalization process. However, the resolution of the DEM used in this study may be typical of the finest that is available for many remote areas in tropical developing countries.

Despite these potential sources of error, the differences between images are readily apparent; the overall accuracy values compare favourably with those obtained by other researchers (e.g. Garcia and Alvarez 1994). Very few researchers working in tropical areas report values above 85 per cent. The classification assessment derived in the Costa Rican study compares favourably with the results from Sader et al. (1991), who worked in different sites represented on the same TM image. In both studies of this region, the number of spectral categories was reduced after classification and before final evaluation. Individual class accuracies were higher for some areas (forest 93\%) and lower for others (second growth and successional 47\%) in the study by Sader et al. (1991) than in the present study. In the Navarro watershed the user's accuracy rose as high as 92 per cent (forest), and did not drop below 61 per cent (shrubs), providing more consistent accuracy results. The somewhat higher Kappa coefficient derived from the non-Lambertian corrected image reflects this consistency (74\%, Sader et al. 1991: 70\%).

While the KAPPA program generated significant F-statistics for nearly all pairs of classified images in the Ecuadorian study, differences in accuracies among treatments were less apparent for the Costa Rican images. In the Costa Rican study, a significant $F$ statistic was generated for the Lambertian and non-Lambertiancorrected images. However, differences between the Kappa statistics for the corrected and non-corrected images were not found to be statistically significant. 
This trend could have resulted from several factors. First, the spatial resolution of the DEM (90 m) utilized for this study was larger than that used in the Ecuadorian study $(30 \mathrm{~m})$. Therefore, the effects of topographic normalization would have been less apparent for the Costa Rican study area than for the Ecuadorian site. Secondly, the sample size of pixels used for the accuracy assessment in the Costa Rican study $(n=257)$ was somewhat smaller than that used in the Ecuadorian study $(n=1000)$. In any event, both visual assessments of the classified images and the overall accuracy percentages indicate that topographic normalization with non-Lambertian treatment enhanced classification accuracies for both study areas.

Classification accuracy could be improved using the non-Lambertian assumption and a more locally derived Minnaert constant (Colby 1991). Using the mask and linear regression capabilities in IDRISI, such an application is possible with the procedures developed in this paper. Future studies should be undertaken to evaluate the effects of both spatial scale and landscape heterogeneity on the calculation of Minnaert constants.

\section{Conclusion}

The study sites in this paper differ considerably with respect to cover types and spatial heterogeneity of the landscape. However, both sites are characterized by rugged, mountainous terrain and are located in tropical environments. The reduction of the topographic effect in these studies, which was obvious in both visual assessments and enhanced classification accuracies, demonstrates the utility of topographic normalization routines based on a non-Lambertian assumption in tropical montane areas.

\section{Acknowledgments}

The Organization of American States, and the US Defense Mapping Agency provided much appreciated support for the research efforts in Costa Rica. We also thank CLIRSEN and the Instituto Geográphico Militar of Quito for providing data sets for the Ecuadorian Project. The Ecuadorian study was funded by the Fulbright Commission of Ecuador and the John D. and Catherine T. MacArthur Foundation. Dr M. H. Hodgson provided excellent technical assistance during the initial stages of research. We are also grateful to Dr S. Sader for providing helpful comments and criticisms of the manuscript. Finally, we thank Dr R. Congalton for providing the KAPPA program used to evaluate differences among Kappa Statistics.

\section{References}

Anderson, J. R., Hardy, E. E., Roach, J. T., and Witmer, R. E., 1976, A land use and land cover classification system for use with remote sensor data. Geological Survey Professional Paper 964, United States Government Printing Office, Washington, DC. Autodesk, 1992, AutoCAD Release 12: Reference manual (San Rafael, CA: Autodesk, Inc.). Balslev, H., 1988, Distribution patterns of Ecuadorian plant species. Taxon, 37, 567-577. Воотн, W., 1989, Monitoring the fate of the forests from space. Science, 243, 1428-1429.

Brondizio, E., Moran, E., Mausel, P., and Wu, Y., 1996, Land cover in the Amazon Estuary: linking of the Thematic Mapper with botanical and historical data. Photogrammetric Engineering and Remote Sensing, 62, 921-929.

Campbell, R. W., Rodriguez, H., and SAder, S. A., 1980, Design of a nationwide natural resource inventory and information system for Costa Rica. Proceedings of the Fourteenth International Symposium on Remote Sensing of Environment, San Jose, Costa Rica, 23-30 April 1980 (Ann Arbor, MI: Environmental Research Institute of Michigan), pp. 325-340. 
Civco, D., 1989, Topographic normalization of Landsat Thematic Mapper imagery. Photogrammetric Engineering and Remote Sensing, 55, 1303-1309.

Colby, J. D., 1991, Topographic normalization in rugged terrain. Photogrammetric Engineering and Remote Sensing, 57, 531-537.

Colby, J. D., 1995, Resolution, fractal characterization and the simulated hydrologic response of a Costa Rican watershed. Unpublished PhD dissertation, Department of Geography, University of Colorado.

Congalton, R. G., 1988, A comparison of sampling schemes used in generating error matrices for assessing the accuracy of maps generated from remotely sensed data. Photogrammetric Engineering and Remote Sensing, 54, 593-600.

Congalton, R. G., 1991, A review of assessing the accuracy of classifications of remotely sensed data. Remote Sensing of the Emnvironment, 37, 35-46.

Cortés, G. V. M., and Oconitrillo, C. G., 1987, Erosion de suelos horticulas en el area de cot y tierra blanca de Cartago. Undergraduate thesis, Department of Geography, University of Costa Rica, San José, Costa Rica.

Crippen, E. R., 1988, The dangers of underestimating the importance of data adjustments in band ratioing. International Journal of Remote Sensing, 9, 767-776.

Eastman, R. J., 1993, ID RISI Update Manual, Version 4.1 (Worcester, MA: Clark University).

Echavarria, F. R., 1993, Remote Sensing of Montane Forest Degradation in Southern Ecuador. Unpublished PhD dissertation, Department of Geography, University of South Carolina.

EKSTRAND, S., 1996, Landsat TM-based forest damage assessment: correction for topographic effects. Photogrammetric Engineering and Remote Sensing, 62, 151-161.

ERDAS, 1994, ERDAS Field Guide (Atlanta, GA: ERDAS, Inc.).

ESRI, 1992, A RC/INFO Version 6.1 (Redlands, CA: Environmental Science Research Institute).

Estes, J. E. (editor), 1983, Manual of Remote Sensing, 2nd edn, Vol. 2 (Falls Church, VA: The Sheridan Press).

FitZPATRICK- LiNS, K., 1980, The accuracy of selected land-use and land-cover maps made from high-altitude photographs and Landsat multispectral imagery. Journal of Research (United States Geological Survey), 6, 23-40.

Fundación Natura, 1992, Acciónes de Desarrollo en Zonas de Influencia de Areas Protegidas (Quito, Ecuador: Fundación Natura).

Garcia, M. C., and Alvarez, D. R., 1994, TM digital processing of a tropical forest region in southeastern Mexico. International Journal of Remote Sensing, 15, 1611-1632.

Hall-Konyves, K., 1987, The topographic effect on Landsat data in gently undulating terrain in southern Sweden. International Journal of Remote Sensing, 8, 157-168.

Hastenrath, S., 1981, The Glaciation of the Ecuadorian Andes (Rotterdam: A. A. Balkema).

Hill, R. A., and Foody, G. M., 1994, Separability of tropical rain-forest types in the Tambopata-Candamo Reserved Zone, Peru. International Journal of Remote Sensing, 15, 2687-2693.

Hodgson, M. E., and Shelley, B. M., 1994, Removing the topographic effect in remotely sensed imagery. ERDAS Monitor, 6, 4-6.

Holben, B. N., and Justice, C. O., 1979, Evaluation and modeling of the topographic effect on the spectral response from nadir pointing sensors. National Aeronautics and Space Administration Technical Memorandum 80305, Greenbelt, Maryland.

Holdridge, L. R., 1967, Life Zone Ecology (San Jose, Costa Rica: Tropical Science Center).

Hugli, H., and FreI, W., 1983, Understanding anisotropic reflectance in mountainous terrain, Photogrammetric Engineering and Remote Sensing, 49, 671-683.

Hutchinson, C. F., 1982, Techniques for combining Landsat and ancillary data for digital classification improvement. Photogrammetric Engineering and Remote Sensing, 48, $123-130$.

JANSSON, M. B., and Rodriguez, A. (editors), 1992, Sedimentological studies in the Cachí Reservoir, Costa Rica. Department of Physical Geography, Uppsala University. UNGI Rapport Nr 81.

Jensen, J. R., 1996, Introductory Digital Image Processing: A remote sensing perspective, 2nd edn (Englewood Cliffs, NJ: Prentice-Hall).

Justice, C. O., and Holben, B., 1979, Examination of Lambertian and non-Lambertian models for simulating the topographic effect on remotely sensed data. National 
Aeronautics and Space Administration Technical Memorandum 80557, Greenbelt, Maryland.

Justice, C. O., Wharton, S. W., and Holben, B. N., 1980, Application of digital terrain data to quantify and reduce the topographic effect on Landsat data. National Aeronautics and Space Administration Technical Memorandum 81988, Greenbelt, Maryland.

Kawata, Y., Ueno, S., and Kusaka, T., 1988, Radiometric correction for atmospheric and topographic effects on Landsat MSS images. International Journal of Remote Sensing, 9, 729-748.

Keating, P. L., 1995, Disturbance regimes and regeneration dynamics of upper montane forests and páramos in the Southern Ecuadorian Andes. Unpublished $\mathrm{PhD}$ dissertation, Department of Geography, University of Colorado.

Keating, P. L., 1997, Mapping vegetation and anthropogenic disturbances in southern Ecuador with remote sensing techniques: implications for park management. 1997 Yearbook of the Conference of Latin Americanist Geographers (University of Texas Press), pp. 77-90.

Kowalick, W. S., Lyon, R. P., and Switzer, P., 1983, The effects of additive radiance terms on ratios of Landsat data. Photogrammetric Engineering and Remote Sensing, 49, 659-669.

Leprieur, C. E., Durrand, J. M., and Peyron, J. L., 1988, Influence of topography on forest reflectance using Landsat Thematic Mapper and digital terrain data. Photogrammetric Engineering and Remote Sensing, 54, 491-496.

Lillesand, T. M., and Kiefer, R. W., 1994, Remote Sensing and Image Interpretation, 3rd edn (New York: John Wiley and Sons).

Malingreau, J. P., Tucker, C. J., and Laporte, N., 1989, AVHRR for monitoring tropical deforestation. International Journal of Remote Sensing, 10, 855-867.

Markham, B. L., and Townshend, J. R., 1981, Land cover classification accuracy as a function of sensor spatial resolution. Proceedings of the Fifteenth International Symposium on Remote Sensing of Environment, Ann Arbor, Michigan, May 1981 (Ann Arbor, MI: Environmental Research Institute of Michigan), pp. 1075-1085.

Mausel, P. W., Kramber, W. J., and Lee, J. K., 1990, Optimum band selection for supervised classification of multispectral data. Photogrammetric Engineering and Remote Sensing, 56, 55-60.

Mausel, P., Wu, Y., Li, Y., Moran, E. F., and Brondizio, E. S., 1993, Spectral identification of successional stages following deforestation in the Amazon. Geocarto International, 4, 61-71.

Meyer, P., Itten, K. I., Kellenberger, T., Sandmeier, S., and Sandmeier, R., 1993, Radiometric corrections of topographically induced effects on Landsat TM data in an alpine environment. ISPRS Journal of Photogrammetry and Remote Sensing, 48, 17-28.

Minnaert, J. L., 1941, The reciprocity principle in lunar photometry. Astrophysics Journal, 93, 403-410.

Mora, C. S., 1987, Analisis preliminar de la Amenaza y Vulnerabilidad Potenciales Generadas por el Rio Reventado y el Deslizamiento de San Blas, Cartago, Costa Rica. Tecnología en Marcha, 9, 19-37.

Moran, E. F., Brondizio, E., Mausel, P., and Wu, Y., 1994, Integrating Amazonian vegetation, land-use, and satellite data. BioScience, 44, 329-338.

Mulders, M. A., De Bruin, S., and Schuilig, B. P., 1992, Structured approach to land cover mapping of the Atlantic zone of Costa Rica using single data TYM data. International Journal of Remote Sensing, 13, 3017-3033.

Paradella, W. R., Da Silva, M. F., De A. Rosa, N., and Kushigbor, C. A., 1994, A geobotanical approach to the tropical rain forest environment of the Carajás Mineral Province (Amazon Region, Brazil), based on digital TM-Landsat and DEM data. International Journal of Remote Sensing, 15, 1633-1648.

Quesada, M. C. A., 1979, Effect of reservoir sedimentation and streamflow modification on firm power generation. Unpublished PhD dissertation, Department of Civil Engineering, Colorado State University.

Richards, J. A., 1986, Remote Sensing Digital Image Analysis: An introduction (New York: Springer-Verlag).

Rosenfield, G. H., and FitzPatrick- Lins, K., 1986, A coefficient of agreement as a measure 
of thematic classification accuracy. Photogrammetric Engineering and Remote Sensing, 52, 223-227.

Sabins, F., 1997, Remote Sensing Principles and Interpretation (New York: Freeman).

SAder, S. A., W Aide, R. B., LaWrence, W. T., and Joyce, A. T., 1989, Tropical forest biomass and successional age class relationships to a vegetation index derived from Landsat TM data. Remote Sensing of Environment, 28, 143-156.

Sader, S. A., Stone, T. A., and Joyce, A. T., 1990, Remote sensing of tropical forests: an overview of research and applications using non-photographic sensors. Photogrammetric Engineering and Remote Sensing, 56, 1343-1351.

S Ader, S. S., Powell, G. V. N., and R appole, J. H., 1991, Migratory bird habitat monitoring through remote sensing. International Journal of Remote Sensing, 12, 363-372.

Simonetr, D. S. (editor), 1983, Manual of Remote Sensing, 2nd edn, Vol. 1 (Falls Church, VA: The Sheridan Press).

Skole, D. L., Chomentowski, W. H., Salas, W. A., and Nobre, A. D., 1994, Physical and human dimensions of deforestation in Amazonia. BioScience, 44, 314-322.

Smith, J., Lin, T., and Ranson, K., 1980, The Lambertian assumption and Landsat data. Photogrammetric Engineering and Remote Sensing, 46, 1183-1189.

Solís, B. H., Murillo, M. W., and Oreamuno, V. R., 1991, Estudio Hidrológico e Hidráulico para el Control de Inundaciones en la Cuenca del Rio Purires: Valle de Guarco. Informe Tecnico, Servicio Nacional de Aguas Subterraneas Riego y Avenamiento: Dirección de Ingeníera, Centro Agronomico Tropical de Investigación y Enseñanza: Proyecto Renarm-Cuencas.

STOHR, C. J., and WeSt, T., 1985, Terrain and look angle effect upon multispectral scanner response. Photogrammetric Engineering and Remote Sensing, 51, 229-235.

Story, M., and Congalton, R. G., 1986, Accuracy assessment: a user's perspective. Photogrammetric Engineering and Remote Sensing, 52, 397-399.

Teillet, P. M., Guidon, B., and Goodenough, D. G., 1982, On the slope-aspect correction of multispectral data. Canadian Journal of Remote Sensing, 8, 84-106.

Toll, D. L., 1984, An evaluation of simulated Thematic Mapper data and Landsat MSS data for discriminating suburban and regional land use and land cover. Photogrammetric Engineering and Remote Sensing, 50, 1713-1724.

Tosi, J. A., 1969, Ecological Map of Costa Rica (San José, Costa Rica: Tropical Science Center).

Townshend, J. R. G., and Justice, C. O., 1986, Analysis of the dynamics of African vegetation using the normalized difference vegetation index. International Journal of Remote Sensing, 7, 1435-1445.

Tucker, C. J., Holben, B. N., and Goff, T. E., 1984, Intensive forest clearing in Rondônia, Brazil, as detected by satellite remote sensing. Remote Sensing of Environment, 15, $255-261$.

Vanclay, J. K., and Preston, R. A., 1990, Utility of Landsat Thematic Mapper data for mapping site productivity in tropical moist forests. Photogrammetric Engineering and Remote Sensing, 56, 1383-1388.

W Aldron, H. H., 1967, Debris flow and erosion control problems caused by the ash eruptions of Irazú Volcano, Costa Rica. Geological Survey Bulletin 1241-I. United States Government Printing Office, Washington DC.

Young, K. R., and León, B., 1995, Connectivity, social actors, and conservation policies in the Central Andes: the case of Peru's montane forests. In Biodiversity and Conservation of Neotropical Montane Forests, edited by S. P. Churchill, H. Balslev, E. Forero and J. L. Luteyn (New York: The New York Botanical Garden), pp. 653-661. 